\title{
INVESTIGATION OF THE RELATION BETWEEN ADHESION AND WATER SENSITIVITY TEST RESULTS
}

\author{
Jozef KOMAČKA ${ }^{1 *}$, Eva REMIŠOVÁ
}

\section{Abstract}

The relation between the results of adhesion and water sensitivity tests was investigated. The tests were performed according to the relevant European standards. Two paving grade bitumens (PGB) with different gradations were used in combination with three adhesion additives and basic, neutral and acidic coarse aggregate. It was concluded that each of the additives enhanced the evaluation of the adhesion regardless of the type of binder and aggregate. All the additives combined with PGB 35/50 improved the water sensitivity results. A better result with $P G B$ 50/70 was observed with only one additive. It was noted that an assessment of the efficiency of an adhesion additive based on a change in the water sensitivity value (ITSR) can contradict a change in the indirect tensile strength. The expected reduction in values with an increase in the coarse aggregate acidity was only confirmed for the adhesion test. The change in the ITSR and the indirect tensile strength of dry and wet samples did not fit the expectations. The correlation between the results of the adhesion and water sensitivity test was low and could not be recommended for predicting the indirect tensile strength of asphalt from rolling bottle test results.

\section{Address}

1 Department of Highway Engineering, Faculty of Civil Engineering, University of Žilina, Žilina, Slovakia

* Corresponding author: jozef.komacka@fstav.uniza.sk

\section{Key words}

- Binder

- Aggregate,

- Water,

- Sensitivity,

- Adhesion,

- Additive.

\section{INTRODUCTION}

Road transport is an important factor in economic growth. The high quality of a road network is a basic assumption enabling the use of this mode of transport. Therefore, it is indispensable to maintain road pavements at an adequate quality level. Various maintenance strategies can be used, but the lifetime of the pavement structure (or rather the critical pavement layer) is always important in the economic analyses. Pavement layers have to fulfill several requirements to produce a lasting and high-quality pavement structure. The fulfillment of the demands for the parameters of a layer is proved via laboratory tests of the material that is intended to be used for the construction of a layer.

As for asphalt pavements, the durability of an asphalt layer depends not only on the quality of the main components of the asphalt mixture (the aggregate and binder) and the design of the asphalt mixture's composition but also on the adhesion between the binder and the aggregate. This is especially important when it is anticipated that the asphalt mixture will be exposed to wet conditions because the occurrence of water worsens the adhesion between the binder and the aggregate and decreases the lifetime of asphalt pavements in service.

Various tests can be used to evaluate the level of the adhesion between the binder and aggregate or the water sensitivity of asphalts. The choice of a method is obviously territorial (Lancaster and Lancaster, 2016); however, the use of different methods can lead to different results and an assessment of the resistance to water (Batista et al., 2009).

Two main standards are applied within Europe. The first (EN 12697-11:2012), relates to the adhesion between the binder and ag- 
gregate, and it is performed on loosely coated aggregate. The second (EN 12697-12:2003) is used to assess the water sensitivity of compacted asphalts based on strength characteristics.

The most used procedure described in EN 12697-11:2012 to test the adhesion between the binder and the aggregate is the rolling bottle test. This method is used to evaluate the degree of binder coverage on uncompacted binder-coated mineral aggregate particles after the effect of mechanically stirring them in the presence of water. The investigations are obviously focused on the effect of the nature of the aggregate and acidity on the level of coverage for various binders (Remišová, 2004; Remišová, 2010; Cuadri et al., 2015). Moreover, the test results are also used to investigate relationships to other test methods focused on the sensitivity to water of the asphalt. The investigation of the relationship to the tensile stiffness (Grönniger et al., 2010; Grenfell, 2014) can be mentioned as an example.

The water sensitivity test (ITSR), which is based on the indirect tensile strength test (ITS) according to EN 12697-23:2003, was used to determine the effect of various adhesion promoters (Valentin et al., 2013) or plastic waste (Ranieri et al., 2017) on improving adhesion. The ITSR test was also included in research focused on the properties of different types of asphalts containing various percentages of reclaimed asphalt without any additives (Komacka et al., 2014) or a warm mix additive (WMA) (Varveri et al., 2014), or to determine the physical properties of WMA mixes produced using foam bitumen technology (Remišová, 2010; Kavussi and Hashemian, 2011; Chomicz-Kowalska et al., 2016). The ITS test results have been used in several projects to investigate the relationships between the ITS and the functional characteristics (resistance to rutting, fatigue and stiffness) of asphalts (Florio et al., 2014) and also in an extensive research study focused on a comparison of several different testing procedures for water/frost sensitivity (Maliszewski et al., 2016). Based on the conclusions of the research findings presented, it can be stated that the value of the ITSR varies largely, mostly depending on the type of binder and its parameters (Komacka et al., 2014; Lancaster and Lancaster, 2016), adhesion additives and aggregate properties (acidity) (Valentová et al., 2016), and also on the thickness of the bitumen film (Burak and Emine, 2007).

The rolling bottle test and the ITSR test are in principle performed on different types of materials, and the parameter used to evaluate the effect of water is also dissimilar. The stripping of the binder from the surface of the aggregate particle in the rolling bottle test can predict the decrease in the contact area covered by the binder between two aggregate particles, which can lead to lower strength parameters of the asphalt. However, the two-way contact between the aggregate particles is often replaced by the contact of an aggregate particle with the asphalt mastic, where the level of the binder stripping is less significant from the point of view of the asphalt strength parameters. Moreover, the water aggressiveness level on the stripping binder is different in these tests, i.e., the whole surface of the aggregate particles is especially not accessible to water, and no stirring occurs during the ITSR test. Therefore, it would be interesting to know whether any relationship between the results of the adhesion and water sensitivity test exists. It could be used to predict the strength parameter of asphalt from the rolling bottle test results and reduce material, time, and equipment costs related to the ITSR test.

Some research on this topic has been performed in various works (Krajewski and Błażejowski, 2012; Krajewski, 2013; Błażejowski et al., 2013; Witczak, 2014), and no relationship was found. However, one freeze/thaw cycle was used in the process of preparing wet samples, but it is not in accordance with the EN 12697-12:2008 test procedure. The freeze/thaw cycle could have an effect on the test results and, subsequently, on the assessment of the relation between the parameters investigated. Therefore, an investigation exactly according to the EN 12697-11:2012, EN 12697-12:2008 and EN 12697-23:2003 European standards was executed. Apart from the main research goal, the effect of additives on the adhesion and the ITS and ITSR values was investigated.

\section{EXPERIMENTAL PROGRAM}

The water sensitivity of three asphalt mixtures (Fig. 1) was tested according to EN 12697-12:2008. The main goal of the water sensitivity experimental program was to investigate the effect of the binder and type of additive on changes in the results for the AC 11 surface course, which consists of basic (alkaline) coarse aggregate and basic fine aggregate. Two paving grade binders with different gradations were tested with and without adhesion additives $(0.4 \%$ dosage). The results from testing the pure bitumen binder properties and the bitumen binder with additives are presented in Tab. 1. A complementary focus was concentrated on the effect of

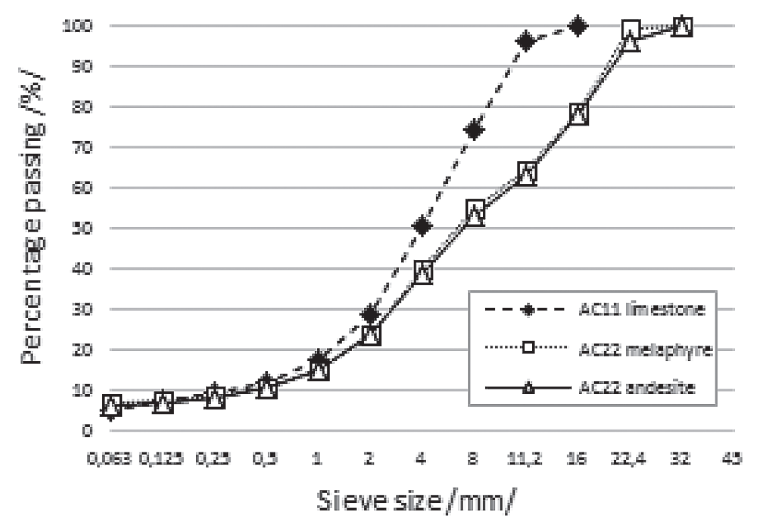

Fig. 1 Particle size distribution of aggregate mixtures.

Tab. 1 Results of tests on the bitumen binder properties.

\begin{tabular}{llll}
\hline Bitumen & Penetration $(0.1 \mathrm{~mm})$ & Softening point $\left({ }^{\circ} \mathrm{C}\right)$ & Penetration index \\
\hline $50 / 70$ & 62 & 48 & -1.24 \\
$50 / 70+$ Wetfix BE & 66 & 47 & -1.34 \\
$50 / 70+$ CWM & 66 & 46 & -1.64 \\
$50 / 70+$ Wetfix AP-47 & 74 & 50.6 & -0.11 \\
\hline $35 / 50$ & 45 & 56.4 & -0.03 \\
$35 / 50+$ Wetfix BE & 44 & 57 & 0.05 \\
$35 / 50+$ CWM & 45 & 56 & -0.06 \\
$35 / 50+$ Wetfix AP-47 & 48 & 55 & -0.29 \\
\hline
\end{tabular}


Tab. 2 Combinations of materials used in the experimental program.

\begin{tabular}{|c|c|c|c|c|c|c|c|c|c|}
\hline Asphalt & $\begin{array}{c}\text { Coarse } \\
\text { aggregate } \\
\text { acidity }\end{array}$ & $\begin{array}{l}\text { Binder } \\
\text { content } \\
(\%)\end{array}$ & PGB $35 / 50$ & $\begin{array}{c}\text { PGB 35/50 } \\
+ \\
\text { Wetfix AP-47 }\end{array}$ & $\begin{array}{c}\text { PGB } 35 / 50 \\
+ \\
\text { CWM }\end{array}$ & $\begin{array}{c}\text { PGB 35/50 } \\
+ \\
\text { Wetfix BE }\end{array}$ & PGB 50/70 & $\begin{array}{c}\text { PGB 50/70 } \\
+ \\
\text { Wetfix AP-47 }\end{array}$ & $\begin{array}{c}\text { PGB 50/70 } \\
+ \\
\text { CWM }\end{array}$ \\
\hline $\begin{array}{l}\text { AC } 11 \\
\text { surface }\end{array}$ & $\begin{array}{l}\text { limestone } \\
\text { (basic) }\end{array}$ & 5.40 & $\mathrm{X}$ & $\mathrm{X}$ & $\mathrm{X}$ & $\mathrm{X}$ & $\mathrm{X}$ & $X$ & $\mathrm{X}$ \\
\hline \multirow{2}{*}{$\begin{array}{l}\text { AC } 22 \\
\text { binder }\end{array}$} & $\begin{array}{l}\text { melaphyre } \\
\text { (neutral) }\end{array}$ & 4.00 & $\mathrm{X}$ & & $\mathrm{X}$ & $X$ & & & \\
\hline & $\begin{array}{c}\text { andesite } \\
\text { (close to acid) }\end{array}$ & 4.10 & $\mathrm{X}$ & & $\mathrm{X}$ & $\mathrm{X}$ & & & \\
\hline
\end{tabular}

Tab. 3 Results of the adhesion and water sensitivity tests with limestone aggregate.

\begin{tabular}{|c|c|c|c|c|c|c|c|c|c|}
\hline Asphalt & $\begin{array}{c}\text { Coarse } \\
\text { aggregate } \\
\text { acidity }\end{array}$ & $\begin{array}{l}\text { Test } \\
\text { result }\end{array}$ & PGB 35/50 & $\begin{array}{c}\text { PGB 35/50 } \\
+ \\
\text { Wetfix AP-47 }\end{array}$ & $\begin{array}{c}\text { PGB } 35 / 50 \\
+ \\
\text { CWM }\end{array}$ & $\begin{array}{c}\text { PGB 35/50 } \\
+ \\
\text { Wetfix BE }\end{array}$ & PGB 50/70 & $\begin{array}{c}\text { PGB 50/70 } \\
+ \\
\text { Wetfix AP-47 }\end{array}$ & $\begin{array}{c}\text { PGB 50/70 } \\
+ \\
\text { CWM }\end{array}$ \\
\hline \multirow{5}{*}{$\begin{array}{l}\mathrm{AC} 11 \\
\text { surface }\end{array}$} & \multirow{5}{*}{ limestone } & adhesion after $6 \mathrm{~h}$ & $85 \%$ & $90 \%$ & $85 \%$ & $85 \%$ & $70 \%$ & $90 \%$ & $85 \%$ \\
\hline & & adhesion after $24 \mathrm{~h}$ & $65 \%$ & $75 \%$ & $75 \%$ & $65 \%$ & $45 \%$ & $75 \%$ & $75 \%$ \\
\hline & & $\mathrm{ITS}_{\mathrm{d}}(\mathrm{MPa})$ & 1.121 & 1.079 & 1.158 & 0.993 & 0.796 & 0.810 & 0.766 \\
\hline & & $\mathrm{ITS}_{\mathrm{w}}(\mathrm{MPa})$ & 0.923 & 0.907 & 0.986 & 0.859 & 0.646 & 0.705 & 0.612 \\
\hline & & ITSR $(\%)$ & 82.3 & 84.1 & 85.1 & 86.5 & 81.2 & 87.0 & 79.9 \\
\hline
\end{tabular}

aggregate acidity, where melaphyre (neutral) and andesite (close to acidic) coarse aggregate were used in the AC 22 mixture for the binder course (Fig.1). The overview of the material combinations used is in Tab. 2.

To complete the input data for the investigation of the relationship sought, rolling bottle tests were performed with the same combinations of materials presented in Tab. 2. A particle size of $8 / 11 \mathrm{~mm}$ was used for the preparation of the test samples.

The samples for the water sensitivity test were compacted by a Marshall hammer $(2 \times 35$ blows $)$ and separated into two groups (dry and wet) based on their bulk densities. Then, the test procedure according to EN 12697-23 was applied (determination of ITS); subsequently, the ITSR values were calculated. As for the rolling bottle test, the preparation of the samples, test procedure, and evaluation were completely in accordance with EN 12697-11:2012.

\section{TEST RESULTS AND DISCUSSION}

A global overview of the test results is shown in Tabs. 3 and 4 . The $I T S_{\mathrm{d}}$ and $I T S_{\mathrm{w}}$ values represent the average of the three values. The adhesion values after $6 \mathrm{~h}$ and $24 \mathrm{~h}$ represent the percentage determined of the aggregate surface covered by a binder (the average of the three values).

The ITSR values for the basic aggregate demonstrate the effect of the binder used and adhesion additives. There is a slight difference between the values that were obtained for the binders without the adhesion additives (the lower value for PGB 50/70). The Wetfix AP-47 additive increases the ITSR values in the case of both binders and concurrently changes the reciprocal relation of the ITSR values (a higher value for PGB 50/70). The CWM additive acts differently because it only increases the ITSR value for PGB 35/50. This leads to a higher distinction between the ITSR values for PGB 35/50 and PGB 50/70. The Wetfix BE additive also enhances the water sensitivity compared to the value of the pure PGB 35/50. It can generally be concluded with reference to the basic aggregate that each of the additives used in the combination with PGB $35 / 50$ improves the water sensitivity of the asphalt. The better results for the PGB 50/70 were only observed with the Wetfix AP-47.

The statements above respect the usual method of evaluating water sensitivity based on the ITSR value. However, the numeric values of the $I T S_{\mathrm{d}}$ and $I T S_{\mathrm{w}}$ are ignored, and their ratio is the only determining parameter. When assuming that the higher percentage of aggregate surface covered by a binder (due to the adhesion additives used) should lead to higher strength parameters of the samples (dry and/or wet) in the water sensitivity test, the effect of the adhesive additives used could be evaluated a little bit differently. No change would occur in the case of PGB 50/70 since both strength parameters $\left(I T S_{\mathrm{d}}\right.$ and $\left.I T S_{\mathrm{w}}\right)$ are higher when Wetfix AP-47 was added to the binder. The positive effect of all the additives used for the PGB $35 / 50$ is not observed when the strength parameters of the asphalt are assessed. The higher $I T S_{\mathrm{d}}$ and $I T S_{\mathrm{w}}$ values were recorded only for the CWM additive. All the values for the Wetfix AP-47 and Wetfix $\mathrm{BE}$ additives are lower when compared to the pure PGB 35/50. The asphalt containing PGB 35/50 with Wetfix BE is a good example of a possible contradictory evaluation based on the ITSR value and the use of the strength of the dry and wet samples. Both the ITS and $I T S_{w}$ values are lower in comparison with the pure PGB 35/50 (and the lowest of all the values), but the ITSR is the highest for all the mixtures with PGB 35/50.

The effect of the acidity of the coarse aggregate on the water sensitivity (ITSR values) is not in conformity with the theoretical assumptions. The expected reduction of ITSR with the increase in the acidity of the coarse aggregate was not confirmed. The disproportion is in the ITSR values for the andesite aggregate. The ITSR value of $88.3 \%$ for the pure PGB 35/50 is the highest (compared to the limestone and melaphyre aggregate) and does not fit the expectations. The same can be stated for the asphalts where the CWM and Wetfix BE additives were added to the PGB 35/50. However, similarly to the limestone aggregate, the positive efficiency of the CWM 
Tab. 4 Results of the adhesion and water sensitivity tests with the melaphyre and andesite aggregate.

\begin{tabular}{|c|c|c|c|c|c|c|}
\hline Asphalt & $\begin{array}{c}\text { Coarse aggregate } \\
\text { acidity }\end{array}$ & Test result & PGB 35/50 & $\begin{array}{c}\text { PGB } 35 / 50 \\
+ \\
\text { CWM }\end{array}$ & $\begin{array}{c}\text { PGB 35/50 } \\
+ \\
\text { Wetfix BE }\end{array}$ & PGB 50/70 \\
\hline \multirow{10}{*}{ AC 22 binder } & \multirow{5}{*}{ melaphyre } & adhesion after $6 \mathrm{~h}$ & $75 \%$ & $80 \%$ & $85 \%$ & $55 \%$ \\
\hline & & adhesion after $24 \mathrm{~h}$ & $45 \%$ & $70 \%$ & $65 \%$ & $15 \%$ \\
\hline & & $\mathrm{ITS}_{\mathrm{d}}(\mathrm{MPa})$ & 0.877 & 0.894 & 0.872 & -- \\
\hline & & $\operatorname{ITS}_{\mathrm{w}}(\mathrm{MPa})$ & 0.709 & 0.739 & 0.787 & -- \\
\hline & & ITSR (\%) & 80.8 & 82.7 & 90.3 & -- \\
\hline & \multirow{5}{*}{ andesite } & adhesion after $6 \mathrm{~h}$ & $70 \%$ & $85 \%$ & $80 \%$ & $65 \%$ \\
\hline & & adhesion after $24 \mathrm{~h}$ & $25 \%$ & $70 \%$ & $60 \%$ & $10 \%$ \\
\hline & & $\mathrm{ITS}_{\mathrm{d}}(\mathrm{MPa})$ & 0.986 & 0.841 & 0.969 & -- \\
\hline & & $\operatorname{ITS}_{\mathrm{w}}(\mathrm{MPa})$ & 0.871 & 0.823 & 0.995 & -- \\
\hline & & ITSR (\%) & 88.3 & 97.9 & 102.7 & -- \\
\hline
\end{tabular}

and Wetfix BE adhesion additives on the ITSR values was also proven for the melaphyre and andesite aggregate. When the ITSR value for the pure PGB 35/50 is compared to the ITSR values valid for the PGB 35/50 with the additive, these latest values are higher.

An evaluation of the effect of the aggregate acidity based on the $I T S_{\mathrm{d}}$ and $I T S_{\mathrm{w}}$ values could not be made for all three categories. As the asphalt containing limestone aggregate had a different composition, only the values for the melaphyre and andesite aggregate can be taken into account. The discrepancy with the expectations, which was observed in the case of ITSR, was also determined for the ITS values. It can be seen that the higher ITS and ITS values are achieved by the asphalt with the andesite (more acidic) aggregate (the only exception is the ITS value for the andesite aggregate and the CWM additive). This is not in accordance with the supposition that the lower strength of the asphalt are achieved with a more acidic coarse aggregate. When the advantages of the additives are assessed, the different effects on the ITS and ITS ${ }_{\mathrm{w}}$ values can be stated. The CWM additive slightly increases the $I T S_{\mathrm{d}}$ and $I T S_{\mathrm{w}}$ values for the melaphyre aggregate but decreases these values for the andesite aggregate. The results with the Wetfix BE additive are a little bit different. This additive decreases the $I T S_{\mathrm{d}}$ value and enhances the $I_{\text {ITS }}$ value in comparison with the pure PGB 35/50. It is valid for both acidities of the coarse aggregate. As with the limestone (basic) aggregate, the problematic use of ITSR as a water sensitivity evaluation parameter can also be observed in the case of the melaphyre and andesite aggregate. Both the ITS values for the asphalt with the CWM additive are lower than those with the pure PGB 35/50. Nevertheless, their better ratio results in a positive evaluation of the contribution of the additive because the ITSR is higher.

When the results of the adhesion tests were assessed, there was a difference between the results after $6 \mathrm{~h}$ and $24 \mathrm{~h}$. As for the limestone, the decrease in the percentage of the surface covered by the binder was from $10 \%$ to $25 \%$. A lower rate of decrease was observed when the adhesive additives were used, which can be assessed as coming from the positive effect of the additives. When the adhesion values of both binders (without the additives) to the limestone aggregate were compared, it can be stated that the adhesion of PGB 50/70 is worse. The use of additives improves the PGB 50/70 adhesion and shifts it to the same values determined for the PGB 35/50.

The difference between the adhesion test results after $6 \mathrm{~h}$ and $24 \mathrm{~h}$ in the case of the melaphyre was in a range of $10-40 \%$. The percentage of the covered surface relating to the PGB $35 / 50$ binder without the additives was lower than the values recorded for this binder with the additives. However, the percentage was higher compared to the values of the PGB 50/70. The highest difference between the percentages of the covered surface determined after 6 $\mathrm{h}$ and $24 \mathrm{~h}$ was found in the case of the andesite aggregate $(15-55$ $\%)$. The worse adhesion of the binders without additives was again proven; moreover, the PGB 50/70 results were worse than those with the PGB 35/50.

The effect of the aggregate acidity was only in accordance with the theoretical assumptions for the binders without the adhesion additives. The highest percentage of the surface covered by the binder was observed in the case of the limestone aggregate, while the lowest was for the most acidic of the aggregate tested (andesite). The use of the CWM and Wetfix BE additives negates the effect of the aggregate acidity because after $24 \mathrm{~h}$, the adhesion values reached approximately the same numbers regardless of the kind of aggregate.

Taking into account the changes in the adhesion and water sensitivity that were discussed above, one can assume that the relationship, if there is one, between these parameters is not strong. Fig. 2 has a global overview of the relation between the percentage of the surface covered by the binder and the ITSR parameter. As can be seen, the determination coefficient $R^{2}$ for the limestone aggregate is low and shows no relation between the parameters. The addition of the values for the melaphyre and andesite would not increase the $R^{2}$ value because these values are scattered. This confirms the negative expectations regarding the relationship and its global validity. Nevertheless, regardless of the spread of the data and the low determination coefficient, one tendency can be observed, i.e., the higher percentage of the surface covered by the binder leads to a higher $I T S R$ value. However, it is necessary to keep in mind that the three lowest percentages of the covered surface represent the ITSR values for the pure binders without the adhesion additives and that the mentioned tendency is the result of the positive effect of the additives. When the data for one binder and one additive are used (across the aggregate acidity), the relationship is no better for the PGB $35 / 50$ with CWM (Fig. 3). On the contrary, there is a very high value of $R^{2}$ in the case of the PGB 35/50 with the Wetfix BE; however, there is a tendency contrary to what was expected.

Similarly to the evaluation above, the relationship between the results of the adhesion and the ITS and ITS values was also investigated. All the $I T S_{\mathrm{d}}$ values were grouped regardless of the type of 


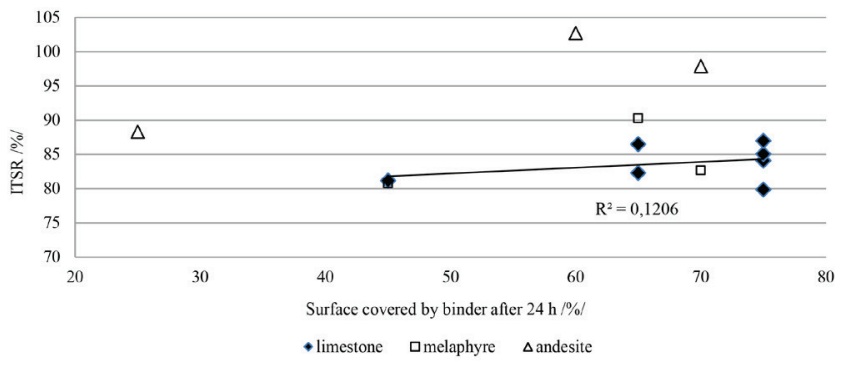

Fig. 2 Relationship between the adhesion and ITSR (all values).

binder and aggregate acidity. The same was done for the ITS $\mathrm{w}_{\mathrm{w}}$ values. Regarding Fig. 4 and the values of the determined coefficients $R^{2}$, it is clear no relationship exists either for the $I T S_{\mathrm{d}}$ or for the $I T S_{\mathrm{w}}$. Likewise, as to the ITSR, there are the values on the left that correspond to the pure binders without the additives (except for the PGB 35/50 with the limestone aggregate). Although the percentage of the surface covered by the binder is very low, the $I T S_{\mathrm{d}}$ (and also the $I T S_{\mathrm{w}}$ ) values are not the lowest, but they are within the total range of all the values. It can be concluded that the percentage of the aggregate surface covered by the binder is not the only parameter predetermining the strength parameters $I T S_{\mathrm{d}}$ and ITS and that it is not decisive from the point of view of this parameter.

\section{CONCLUSIONS}

The research focused on the relationship between the results of the adhesion and water sensitivity tests confirmed the existing knowledge related to the adhesion test, and some new findings were revealed for the water sensitivity test.

The rolling bottle tests proved the better adhesion of the PGB 35/50 to the aggregate compared to the PGB 50/70. The effect of the aggregate acidity on the adhesion of the pure binders was identified and was in accordance with the current knowledge (a more acidic aggregate leads to a lower percentage of the aggregate surface being covered by the binder). The positive efficiency of the adhesion additives was also observed. It was concluded that each of the additives used enhanced the adhesion regardless of the type of binder and aggregate. The use of the CWM and Wetfix BE additives negates the effect of the aggregate acidity because the adhesion values after $24 \mathrm{~h}$ reached approximately the same numbers regardless of the kind of aggregate.

The water sensitivity test results were not always in accordance with the adhesion test results. The change in values due to the type of binder, the aggregate acidity, and the type of adhesion additive was also determined, but the difference sometimes had a tendency contrary to what was in the adhesion test. Thus, it can be stated that all the additives used in combination with the PGB 35/50 improved the water sensitivity results. A better result with the PGB 50/70 was only observed with one additive. However, it can be noted that the assessment of the adhesion additive's efficiency based on the change

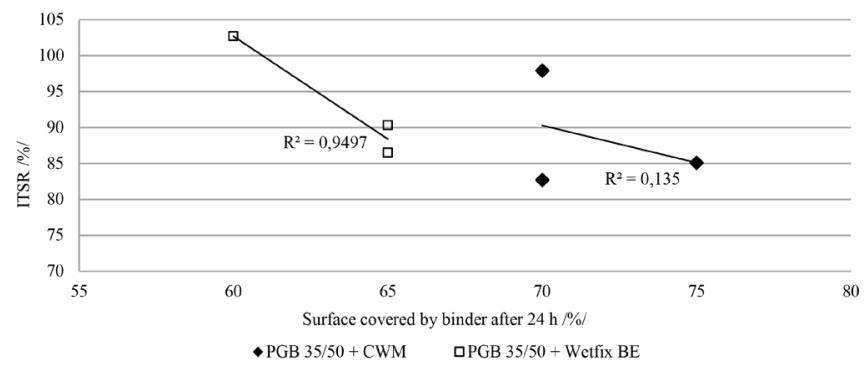

Fig. 3 Relationship between the adhesion and ITSR for the PGB 35/50 binder and two additives.

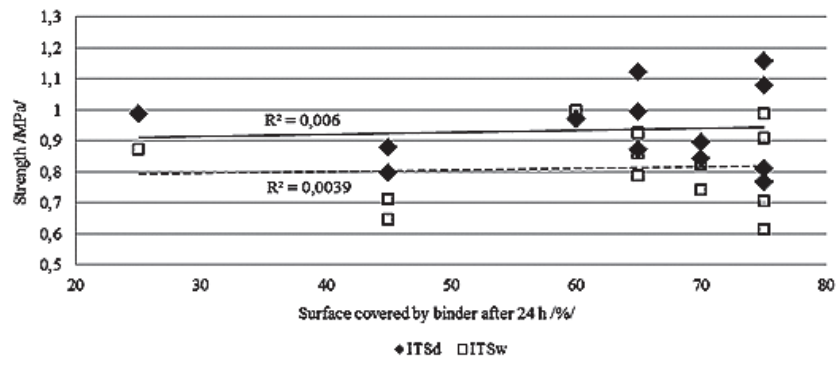

Fig. 4 Relationship between the adhesion and ITS or $\operatorname{ITS}_{w}$ (all values).

in the ITSR value can contradict an evaluation that takes the change in the indirect tensile strength into account. As for the expected reduction of the ITSR, ITS , and ITS values with the increase in the coarse aggregate acidity, this was not confirmed.

A negative result has to be stated regarding the correlation between the results of the adhesion and water sensitivity tests. The determination coefficient between the percentage of the aggregate surface covered by the binder and the ITSR value was low. However, a slight tendency to a higher ITSR value with the increase in the percentage of the covered surface can be deduced as the result of the positive effect of the adhesion additives. Nevertheless, the relationship between these two parameters is not sufficiently strong and could not be recommended for predicting the indirect tensile strength of asphalt from the rolling bottle test results. The same conclusion can be reached for the relationship between the percentage of the aggregate surface covered by the binder and the $I T S_{\mathrm{d}}$ or $I T S_{\mathrm{w}}$ value. Moreover, no tendency to higher values $\left(I T S_{\mathrm{d}}\right.$ or $\left.I T S_{\mathrm{w}}\right)$ mentioned in the case of ITSR was noted for the binder with additives.

\section{Acknowledgment}

This work was supported by the Scientific Grant Agency of the Ministry of Education, Science, Research and Sport of the Slovak Republic and the Slovak Academy of Science under Grant [VEGA 1/0300/17]. 


\section{REFERENCES}

Batista, F. A. - Antunes, M. L. - Fonseca, P. (2009) Assessment of water sensitivity of asphalt rubber mixtures for wearing course. 7th International RILEM Symposium on Advanced Testing and Characterisation of Bituminous Materials, 27-29 May 2009, Rhodes, Greece, 323-330.

Błażejowski K. - Olszacki J. - Peciakowski H. (2013) Wyniki programu badawczego dotyczacego przyczepności asfaltu do kruszy$w a$ (The results of a research programme on bitumen-aggregate affinity). Proceedings of eSeMA 2013, 20-22 Feb 2013, Zakopane, Poland.

Burak, S. - Emine, A. (2007) Effect of asphalt film thickness on the moisture sensitivity characteristics of hot-mix asphalt. Building and Environment 42: 3621-3628.

Cuadri, A. A. et al. (2015) Chemically modified bitumens with enhanced rheology and adhesion properties to siliceous aggregates. Construction and Building Materials 93: 766-774.

EN 12697-11 (2012) Bituminous mixtures. Test methods for hot mix asphalt. Part 11: Determination of the affinity between aggregate and bitumen.

EN 12697-12 (2008) Bituminous mixtures. Test methods for hot mix asphalt. Part 12: Determination of the water sensitivity of bituminous specimens.

EN 12697-23 (2003) Bituminous mixtures. Test methods for hot mix asphalt. Part 23: Determination of the indirect tensile strength of bituminous specimens.

Florio, E. et al. (2014) American and European Mix Design Approaches Combined. Use of NCHRP Performance Indicators to Analyze Comité Européen de Normalisation Test Results. Transportation Research Record 2447: 83-91.

Grenfell, J. et al. (2014) Assessing asphalt mixture moisture susceptibility through intrinsic adhesion, bitumen stripping and mechanical damage. Road Materials and Pavement Design 15(1): 131-152.

Grönniger, J. - Wistuba, M. P. - Renken, P. (2010) Adhesion in bitumen-aggregate-systems: New technique for automated interpretation of rolling bottle tests. Road Materials and Pavement Design 11(4): 881-898.

Chomicz-Kowalska, A. - Gardziejczyk, W. - Iwański, M.M. (2016) Moisture resistance and compatibility of asphalt concrete produced in half-warm mix asphalt technology with foamed bitumen. Construction and Building Materials 126, 108-118.

Kavussi, A. - Hashemian, L. (2011) Properties of wma-foam mixes based on major mechanical tests. Journal of Civil Engineering and Management 17(2): 207-216.

Komacka, J. et al. (2014) Influence of reclaimed asphalt with polymer modified bitumen on properties of different asphalts for a wearing course. ICTI 2014 Sustainability, eco-efficiency and conservation in transportation infrastructure asset management, 22-25 April 2014, Pisa, Italy, 179-185.

Krajewski M. - Błażejowski K. (2012) Odporność mma na działanie wody - porównanie procedur $i$ zastosowanie praktyczne (The resistance of asphalt mixtures for water - a comparison of procedures and practical applications). Proceedings of eSeMA 2012, 16-17 Feb 2012, Zakopane, Poland.

Krajewski M. (2013) Test results of adhesion testing. Proceedings of eSeMA 2013, 20-22 Feby 2013, Zakopane, Poland.

Lancaster, I. Mi. - Lancaster, I. Ma. (2016) The effect of binder composition and properties on the water sensitivity of asphalt mixtures. E\&E Congress 2016 - 6th Eurasphalt \& Eurobitume Congress, 1-3 June 2016, Prague, Czech Republic, DOI: dx.doi. org/10.14311/EE.2016.187.

Maliszewski, M. - Zofka, A. - Maliszewska, D. - Sybilski, D. (2016). Asphalt mixture sensitivity to water and frost. RILEM Bookseries. Kluwer Academic Publishers, 177-188.

Ranieri, M. et al. (2017) Asphalt surface mixtures with improved performance using waste polymers via dry and wet processes. Journal of Materials in Civil Engineering 29(10): article number 04017169

Remišová, E. (2004) Theory and measurements of bitumen binders adhesion to aggregate. Komunikacie-Communications 6(1): 5863.

Remišová, E. (2010) Zmeny v stanoveni citlivosti asfaltových zmesí na vodu (The changes in determination of water sensitivity of bituminous mixes). Civil and Environmental Engineering 6(2): $78-86$.

Valentin, J. - Vavricka, J. - Valentová, T. (2013) Influence of various adhesion promoters on asphalt behavior by assessment of water sensitivity. 9th International Conference on the Bearing Capacity of Roads, Railways and Airfields, 25-27 June 2013, Trondheim, Norway, 735-744.

Valentová, T. - Altman, J. - Valentin, J. (2016) Impact of asphalt ageing on the activity of adhesion promoters and the moisture susceptibility. Transportation Research Procedia 14: 768-777.

Varveri, A. et al. (2014) Report on the results of the laboratory tests for the RA mixtures without considering the effect of ageing. Deliverable No. 2 of the project EARN - Effects on Availability of Road Network.

Witczak, S. (2014) Prawdy i mity zwiazane z powinowactwem pomiędzy asfaltem i kruszywem. (Truths and myths about bitumen-aggregate affinity). Proceedings of eSeMA 2014, Feb 2014, Zakopane, Poland. 